\title{
SOME PROPERTIES OF PIG FOLLICULAR FLUID
}

\author{
C. A. SHIVERS,* C. B. METZ AND C. LUTWAK-MANN $\dagger$ \\ Institute for Space Biosciences, Florida State University, \\ Tallahassee, Florida, U.S.A.
}

(Received 21st December 1963)

Summary. Comparisons of the antigenic and chemical composition of pig blood and follicular fluid are reported. Follicular fluid was found to contain less protein, protein-bound orcinol-reactive carbohydrate, reducing sugar and sialic acid, but a little more acid-soluble phosphate, than blood serum. Fructose and ergothioneine were not present in appreciable amounts in either follicular fluid or blood serum

Immunoelectrophoretic analysis showed that both follicular fluid and blood serum contained at least ten different antigenic components. Most of these were common to both but two of the serum antigens were not found in the follicular fluid. The follicular fluid antigen absent from serum appears to be fibrinogen.

Washings from the uteri of adult non-pregnant pigs contained at least six antigens most of which were not found in either follicular fluid or blood.

\section{INTRODUCTION}

Several aspects of the nature of the follicular fluid from large domestic animals have been studied recently. These include the chemical composition (LutwakMann, 1954), electrophoretic behaviour of proteins (Caravaglios \& Cilotti, 1957), and the content of certain steroids (Short, 1960, 1961, 1962). Ready access to quantities of material permitted us to do some immunochemical and a few biochemical analyses on pig follicular fluid and make qualitative and quantitative comparisons with pig blood plasma, serum and uterine washings. The immunological findings reveal a number of antigens common to both blood and follicular fluid and, in addition, some antigens specific to blood.

\section{MATERIALS AND METHODS}

Follicular fluid was obtained from the ovaries of adult, non-pregnant sows at slaughter by aspiration of follicles measuring 3 to $5 \mathrm{~mm}$ in diameter. Cellular debris and erythrocytes that occasionally contaminated the follicular fluid were removed by centrifugation at $10,000 \mathrm{~g}$ for $10 \mathrm{~min}$ at $0^{\circ} \mathrm{C}$. It was found by spectroscopic measurement that the content of haemoglobin in the follicular

\footnotetext{
* Present address: Department of Zoology, University of Tennessee, Knoxville, Tennessee, U.S.A. $\dagger$ Present address: Unit of Reproductive Physiology and Biochemistry (Agricultural Research Council), Cambridge.
} 
fluid never exceeded that of blood diluted $1: 1000$; such an admixture of blood would not be expected materially to affect determinations made on follicular fluid. Blood was collected by heart puncture and either treated with oxalate for preparation of plasma or allowed to clot to yield serum.

To obtain uterine secretion non-pregnant uteri were examined for the presence of free fluid. However, free uterine fluid was detected in only one of the several uteri inspected. Therefore, the secretion coating the surface of the endometrium was collected by flushing. The uteri were cut into $20-$ to $30-\mathrm{cm}-$ long segments each of which was flushed with about $20 \mathrm{ml}$ of Ringer's solution buffered with $0.02 \mathrm{M}$-phosphate to $\mathrm{pH} 7 \cdot 4$. These 'uterine washings' were pooled and used for experiments. All experimental fluids were stored by deep freezing.

Antisera were prepared in rabbits against pig follicular fluid, pig blood serum and uterine washings. Rabbits weighing 4 to $5 \mathrm{~kg}$ were injected subscapularly with $1.5 \mathrm{ml}$ of the antigen emulsified with an equal volume of Freund's complete adjuvant (Difco). A booster injection consisting of the same amount of antigen and adjuvant was given 10 days later. A trial bleeding was made 3 weeks after the second injection. At that time the antibody titre was sufficiently strong to produce precipitates in agar gel diffusion tests. Two rabbits were used for the production of antisera against each of the experimental fluids. The sera were not pooled. Blood for control rabbit serum was drawn from the ear vein prior to antigen injection. No cross-reaction in agar gel diffusion or immunoelectrophoretic tests was observed between normal rabbit serum and the experimental fluids from pigs.

All control and immune gamma globulin samples were stored frozen. Before use each was dialysed against 0.05 ionic strength veronal-acetate buffer, $\mathrm{pH} 8 \cdot 6$, to adjust the $\mathrm{pH}$ and ionic strength. To remove or neutralize specific antibodies the antisera were absorbed by mixing with various dilutions of antigen in glass tubes for $24 \mathrm{hr}$ at $4^{\circ} \mathrm{C}$. Precipitates were removed by centrifugation. Preliminary tests indicated that an equal volume of the experimental pig fluids was sufficient to render rabbit serum non-precipitating for the absorbing fluids in agar gel diffusion tests. Unabsorbed gamma globulin preparations were mixed with an equal volume of veronal-acetate buffer before analysis, to maintain equal antibody dilutions in the absorbed and unabsorbed samples.

Immunoelectrophoresis experiments were performed by a modification of the procedure of Metz \& Kohler (1960), using 1\% Ionagar (Difco) made up in 0.05 ionic strength veronal-acetate buffer, $\mathrm{pH} 8.6$. The agar plates were prepared by pouring $15 \mathrm{ml}$ melted agar on $3 \frac{1}{4} \times 4$ in. smoothcut glass plates. Troughs were moulded in with a vertical microscope slide template. Circular wells for antigen receptacles were cut with a glass pipette $2 \mathrm{~mm}$ in diameter.

To achieve electrophoretic migration the preparations were subjected to a current of $30 \mathrm{~mA}$ for $3 \mathrm{hr}$. After the completion of electrophoretic runs the agar plates were either stained immediately with triple protein stain consisting of thiazine red, amidoschwarz and light green (Crowle, 1961) to determine the electrophoretic mobility of proteins directly, or antiserum was added to the plates to determine the antigenic structure of the fluids. The immunoelectrophoretic plates were allowed to develop for 4 days at room temperature and were photographed for a permanent record. 
The following chemical determinations were performed: protein (Gornall, Bardawill \& David, 1949); reducing sugar (Hagedorn \& Jensen, 1923); fructose (Roe, 1934); citric acid (Speck, Moulder \& Evans, 1946); ergothioneine (Mann \& Leone, 1953); acid-soluble phosphate (Berenblum \& Chain, 1938); orcinol-reactive carbohydrate (Winzler, 1955); sialic acid (Svennerholm, 1957).

In the text below, the following abbreviations will be used: follicular fluid, FF; pig blood plasma, BP; pig blood serum, Bs; uterine washings, uw.

\section{RESULTS}

\section{Electrophoretic behaviour of pig follicular fuid}

FF and Bs were compared by direct electrophoresis in agar blocks. A preparation stained after a 3-hr run showed at least four components (Pl. 1, Fig. 1) of which two in each sample migrated toward the anode and two toward the cathode. Although the volumes of the fluid samples were equal, the staining intensity of the spot nearest the origin and toward the anode was stronger in Bs than the corresponding spot in FF. Moreover, the spot nearest the origin and toward the cathode was more pronounced in $\mathrm{FF}$ than the corresponding spot in Bs. Otherwise no marked differences were detected between FF and Bs by this direct electrophoretic procedure. The result is in substantial agreement with the findings made by Caravaglios \& Cilotti (1957) in cow follicular fluid.

\section{Antigenic properties of pig follicular fluid}

FF and Bs were both strongly antigenic in rabbits as shown by the appearance of strong precipitin bands in preliminary agar gel diffusion (Ouchterlony) tests. To compare the antigenic properties in more detail, the fluids were subjected to immunoelectrophoretic analysis. FF and Bs were each found to contain at least ten different antigenic components most of which were common to both FF and Bs.

However, FF and Bs each exhibited one or more specific antigens in addition to the common components. In a series of five immunoelectrophoretic runs anti-pig serum rabbit antibody consistently produced ten to twelve precipitin arcs when reacted against the homologous antigenic material, pig serum, but yielded only eight to ten precipitin arcs with FF and one to two arcs with Uw. This suggests that BS contains at least one or two antigenic components that are not present in FF, and eight to ten components not shared with Uw. Some of these relations are shown in Pl. 1, Fig. 2.

In a series of five additional reciprocal immunoelectrophoretic experiments anti-pig FF antibody yielded twelve to fourteen precipitin arcs with the homologous antigenic material, follicular fluid, but only ten to twelve arcs with BS, and two with Uw. The additional arcs with FF indicate one to two antigens in FF that are not present in serum, and eight to ten components absent from Uw. Pl. 1, Fig. 3 is a photograph of a system showing some of these arcs.

To confirm the presence of specific antigens in the fluids the immunoelectrophoretic experiments were repeated using absorbed sera. As expected, antisera absorbed with the fluid originally used as immunizing antigen, produced no precipitin arcs with any of the fluids. The absence of such precipitin arcs 
between the homologous fluid and the absorbed serum served as a check for the completeness of absorption. When absorbed with a heterologous fluid, both anti-Bs antibody and the anti-FF antibody produced precipitin arcs with the homologous antigen. Thus, in three experiments, anti-pig serum yielded two arcs with Bs, following absorption with FF (Pl. 1, Fig. 4). These arcs evidently corresponded to the Bs specific arcs in systems like that illustrated in Pl. 1, Fig. 2. Similarly, in three experiments anti-FF rabbit serum produced one precipitin arc with $\mathrm{FF}$, following absorption with Bs. Unlike the characteristic components of BS, that component of FF migrated toward the cathode (Pl. 1, Fig. 5). BP also produced a precipitin arc in this position when reacted with the absorbed serum. This suggests that the antigenic component of FF that is lacking in serum may be fibrinogen. Additional evidence for this was found, in experiments in which after repeated freezing and thawing a precipitate formed in most samples of FF. This was separated by centrifugation, resuspended in saline and used as test antigen. When this material was subjected to immunoelectrophoresis against anti-FF serum which had previously been absorbed with BS, a strong precipitin arc formed in the position of the specific FF antigen referred to in Pl. 1, Fig. 5.

\section{Antigenic properties of pig uterine wash-fuid}

Two comparable experiments were done with antisera prepared against uw. This material produced up to six precipitin arcs with the homologous antisera in immunoelectrophoretic experiments. By appropriate absorption of the antiuw serum it was found that at least four of the antigens of uw were not present in Bs, and two were absent from FF.

\section{Comparison of certain chemical constituents in pig follicular fluid and blood serum}

When the protein content of FF was estimated in relation to Bs, it was found to vary from 74.7 to $77.5 \%$ of that present in Bs. There was a similar difference in the protein-bound orcinol-reactive carbohydrate (expressed in glucose equivalents, $\mathrm{mg} / 100 \mathrm{ml}$ ), $128 \mathrm{in} \mathrm{FF}$ and 152.5 in Bs. The concentration of other constituents in FF and Bs respectively, was as follows $(\mathrm{mg} / 100 \mathrm{ml})$ : reducing sugar, 44 and 97 ; acid-soluble phosphate, 8.8 and 6.4 ; citric acid, 1.3 and 1.25 ; sialic acid, 77 and 91 ; no fructose or ergothioneine was found in FF; BS contained only trace amounts of these two constituents.

\section{DISCUSSION}

A variety of physiological and biochemical investigations including some involving the use of isotope tracers (Kaulla, Aikawa \& Pettigrew, 1958; Peckham \& Kiekhofer, 1959) and foreign antigens (Glass, 1963), have led to the conclusion that the mammalian ovarian follicles contain most if not all of the dissolved constituents of the blood. It is likely that these pass from the blood to the follicular fluid by a filtration process. In addition, follicular fluid contains a high concentration of steroid hormones (Short, 1962) secreted by the follicle cells, and possibly components from disintegrating follicle cells.

The availability of pig follicular fluid made it possible to determine some of 
its constituents and compare the values obtained with those of the blood serum and plasma. In addition, the high resolving power of immunological methodology, notably immunoelectrophoresis, seemed suitable for evaluating qualitative similarities and differences between these fluids at the macromolecular level.

Such chemical determinations as were done indicate that on the whole there are no major differences in the composition of pig follicular fluid and blood serum, except that the follicular fluid contains somewhat less protein, proteinbound carbohydrate, and sialic acid. The relatively low value for reducing sugar in samples of follicular fluid may perhaps be accounted for by a glycolytic breakdown of glucose during the interval ensuing between collection of material and chemical analysis.

The immunoelectrophoretic analysis shows that both follicular fluid and blood contain ten to twelve different antigens. Nearly all of these appear to be common to both follicular fluid and blood. However, certain antigenic differences were noted. Thus, follicular fluid contains one antigenic substance absent from blood serum. It is likely that this antigen is fibrinogen since it is present in plasma and since a coagulum obtained by freeze-thawing of follicular fluid produced a single precipitin arc with pig serum-absorbed, anti-follicular fluid antibody. This study failed to demonstrate any antigens in follicular fluid that are not present in blood plasma. It would appear, therefore, that if antigenic material in substantial amounts is contributed to follicular fluid from sources other than blood, e.g. follicle cells, this fails to incite production of antibodies in rabbits, distinguishable from the antibodies directed against blood antigens.

Although follicular fluid appears to contain no unique antigens as compared to blood, blood serum does contain two antigens that were not demonstrable in follicular fluid. Characterization and identification of these serum antigens would require further analysis. It is possible that these are constituents of the B-lipoprotein fraction of serum, which Caravaglios \& Cilotti (1957) failed to find in bovine follicular fluid.

The experiments performed with antisera prepared against uterine washings show that the uterine wash-fluids contain several antigens and that a number of these are not present in either blood or follicular fluid. Presumably, they are products of the endometrial gland secretion. How direct the origin of the common antigens is with respect to the blood, is uncertain. It should be noted that antibody against uw produced six precipitin arcs when tested against uw. The absorption experiments showed that four of the corresponding uw antigens were not present in Bs and two were absent from FF. This would imply that FF has two more antigens than Bs. Yet the tests with the other sera showed FF to have only one more such antigen. Further experiments would be required to resolve this apparent inconsistency.

\section{ACKNOWLEDGMENTS}

This work was supported by Grant No. NSG-173-62 of the National Aeronautics and Space Administration and National Science Foundation Grant No. G-9150. Contribution No. 022 of the Institute for Space Biosciences. 
The authors are indebted to the Rea Serum Company, Tallahassee, Florida for the pig materials used in the study.

\section{REFERENCES}

Berenblum, I. \& Ghain, E. (1938) An improved method for the colorimetric determination of phosphate. Biochem. 7. 32, 295.

Caravaglios, R. \& Cirotri, R. J. (1957) A study of the proteins in the follicular fluid of the cow. $\mathcal{F}$. Encodrin. 15, 273.

Crowle, A. J. (1961) Immunodiffusion. Academic Press, London.

GLass, L. (1963) Transfer of native and foreign serum antigens to oviducal mouse eggs. Amer. Zool. $3,135$.

Gornall, A. G., Bardawill, C. J. \& David, M. M. (1949) Determination of serum proteins by means of the biuret reaction. F. biol. Chem. 177, 751 .

Hagedorn, H. G. \& Jensen, B. N. (1923) Zur Mikrobestimmung des Blutzuckers mittels Ferricyanid. Biochem. Z. 135, 46.

Kaulla, K. N., Aikawa, J. K. \& Pettigrew, J. D. (1958) Concentration in the human ovarian follicular fluid of radioactive tracers and drugs circulating in the blood. Nature, Lond. 182, 1238.

LUTWAK-MANN, C. (1954) Note on the chemical composition of bovine follicular fluid. F. agric. Sci. 44, 477.

Mann, T. \& Leone, E. (1953) Studies on the metabolism of semen. Biochem. 7. 53, 140.

METz, G. B. \& KohLER, K. (1960) Antigens of Arbacia sperm extracts. Biol. Bull., Woods Hole, 119, 202.

Peскнам, B. \& Kiekнofer, W. (1959) The movement of tritium-labelled water in neoplastic cystic structures. Amer. F. Obstet. Gynec. 78, 1012.

RoE, J. J. (1934) A colorimetric method for the determination of fructose in blood and urine. F. biol. Chem. 107, 15.

Short, R. V. (1960) Steroids present in the follicular fluid of the mare. F. Endocrin. 20, 147.

SHORT, R. V. (1961) Steroid concentrations in the follicular fluid of mares at various stages of the reproductive cycle. 7 . Endocrin. 22, 153.

Short, R. V. (1962) Steroids present in the follicular fluid of the cow. F. Endocrin. 23, 401.

SPECK, J. F., Moulder, J. W. \& Evans, E. A. (1946) The biochemistry of the malaria parasite. V. Mechanisms of pyruvate oxidation in the malaria parasite. F. biol. Chem. 164, 119.

SvenNerholm, L. (1957) Quantitative estimation of sialic acid. II. A colorimetric resorcinol-hydrochloric acid method. Biochim. biophys. Acta, 24, 604.

WinzLer, R. J. (1955) Determination of serum glycoprotein. Meth. biochem. Anal. 2, 290.

\section{EXPLANATION OF PLATE 1}

Frg. 1. Photograph showing the electrophoretic mobilities of proteins in pig follicular fluid (FF) and pig blood serum (Bs). The samples were run simultaneously on a glass plate in agar. Proteins were stained following electrophoresis.

Frg. 2. Immunoelectrophoresis of $\mathrm{Uw}$, BS and FF (circular wells) with unabsorbed antiserum against pig serum (troughs).

Fig. 3. Immunoelectrophoresis of UW, BS and FF (circular wells) with unabsorbed antiserum against follicular fluid (troughs).

FIG. 4. Immunoelectrophoresis of BP, Bs and FF (circular wells) with follicular fluid absorbed, anti-pig serum (troughs).

FIG. 5. Immunoelectrophoresis of BP, BS and FF (circular wells) with pig serum absorbed, anti-follicular fluid serum. 
PLATE $]$

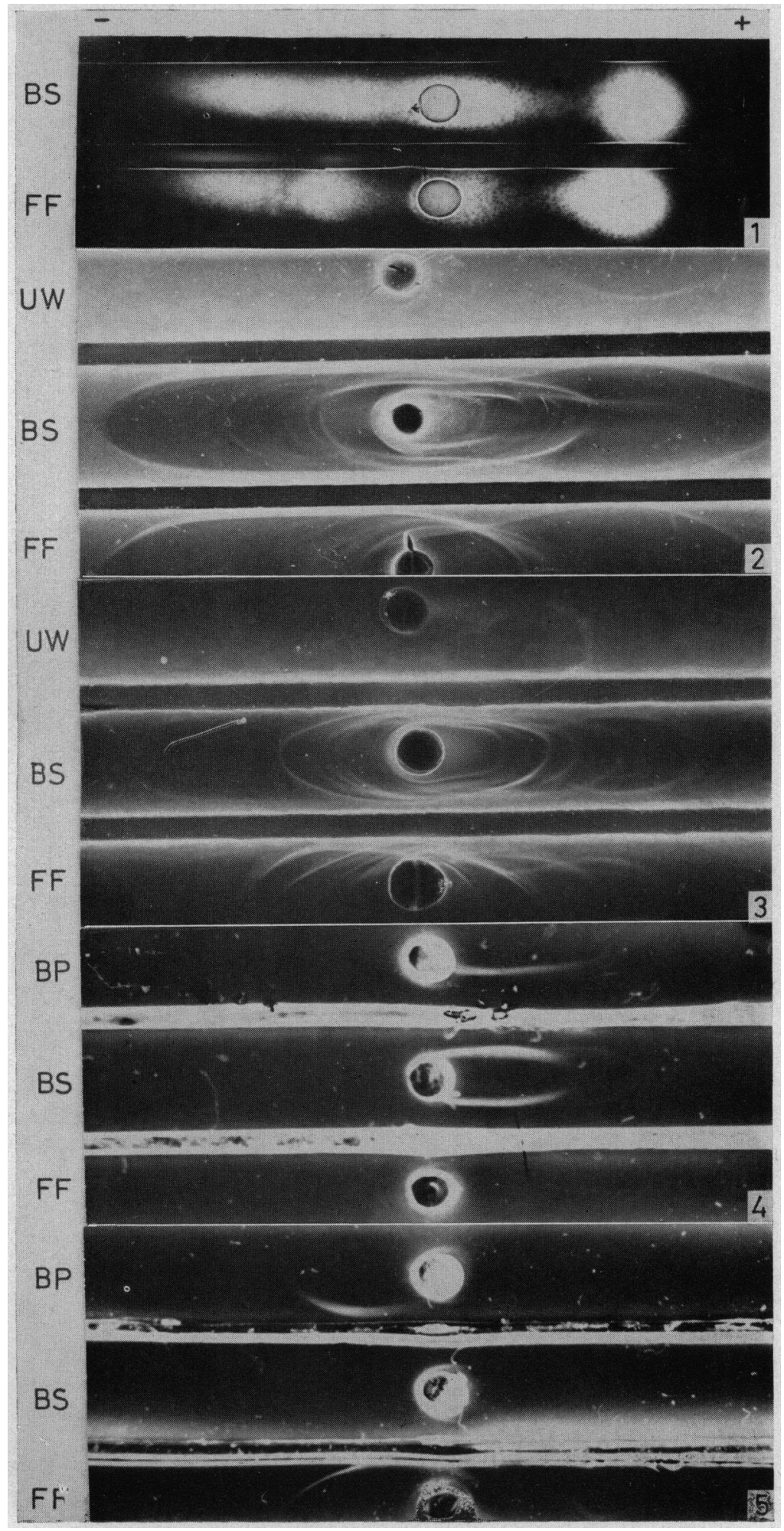

